\title{
COMUNICAÇÃO
}

\section{CARACTERIZAÇÃO FÍSICO-QUÍMICA DOS FRUTOS DE GENÓTIPOS DE BANANEIRA PRODUZIDOS EM BOTUCATU-SP}

\author{
Fruit physicochemical characterization of banana genotypes produced in Botucatu-SP
}

\author{
Dayana Portes Ramos', Sarita Leonel ${ }^{2}$, Martha Maria Mischan ${ }^{3}$
}

\begin{abstract}
RESUMO
O conhecimento dos atributos pós-colheita dos frutos de novos genótipos é uma importante informação que auxilia o melhorista em sua tomada de decisão. Neste trabalho, objetivou-se avaliar as características físico-químicas de frutos de genótipos de 3 grupos genômicos de bananeira: 'Nanicão-IAC-2001', 'Grande Naine', 'Caipira' e 'Nam' (AAA); 'Maçã', 'Thap Maeo', 'Prata Anã' e 'Prata Zulu' (AAB); 'Fhia 01', 'Fhia 18', 'Prata Graúda' e 'Tropical' (AAAB), no município de Botucatu-SP. As características avaliadas foram: textura, $\mathrm{pH}$, acidez titulável, sólidos solúveis, açúcares solúveis totais, teores de amido e potássio. Foi adotado o delineamento experimental inteiramente casualizado, com 12 tratamentos (genótipos), cinco repetições, sendo que em cada repetição utilizaram-se cinco frutos. Utilizou-se o teste de tukey $(P \mathrm{~d}$ ” 0,05$)$ para a comparação entre médias de genótipos, dentro de cada grupo genômico. Os resultados mostraram que no grupo AAA, Nam se destacou apresentando frutos mais firmes, com maior teor de sólidos solúveis e amido. Do grupo AAB, 'Prata Zulu' apresentou frutos mais firmes, com maior teor de açúcares solúveis totais e amido e menor acidez. No grupo dos híbridos AAAB, 'Tropical' apresentou maior teor de potássio e amido, no entanto, menor teor de sólidos solúveis e açúcares solúveis totais.
\end{abstract}

Termos para indexação: Musa sp., qualidade dos frutos, cultivares, híbridos.

\begin{abstract}
The knowledge of the post-harvest characteristics of new banana genotypes is important an information that helps the breeder in making a decision. This work had the objective of evaluating the fruit physical and chemical characteristics of genotypes of three banana genomic groups: 'Nanicão-IAC-2001', 'Grande Naine', 'Caipira', and 'Nam' (AAA); 'Maçã', 'Thap Maeo', 'Prata Anã', and 'Prata Zulu' (AAB); 'Fhia 01', 'Fhia 18', 'Prata Graúda', and 'Tropical' (AAAB) in Botucatu region, São Paulo state, Brazil. The evaluated characteristics were: firmness, $\mathrm{pH}$, titratable acidity, soluble solids, total soluble sugars, starch, and potassium contents. The experimental design was completely randomized, with 12 treatments (genotypes), five replications and each replication consisting of five fruits. The method used was the Tukey test $(P \mathrm{~d}$ " 0.05$)$ for the characterization of genotypes within each genomic group. The results showed that in the AAA group, Nam stood out due to the firmest fruits and the highest levels of soluble solids and starch. In the AAB group, 'Prata Zulu' presented the firmest fruits, the highest levels of total soluble sugars and starch, and the lowest acidity. In the AAAB group of hybrids, 'Tropical' had highest content of potassium and starch, however, lowest content of soluble solids and total soluble sugars.
\end{abstract}

Index terms: Musa sp., fruit quality, cultivars, hybrids.

(Recebido em 11 de julho de 2008 e aprovado em 19 de março de 2009)

A bananicultura brasileira possui grande importância econômica e social, destacando-se como segundo produtor mundial. No entanto, apresenta poucos cultivares com potencial agronômico para exploração comercial, com alta produtividade, tolerantes às pragas e doenças e que apresentem frutos com boas características pós-colheita e organolépticas.

Uma das estratégias para a solução dos problemas mencionados é a seleção de novos genótipos, mediante o melhoramento genético. Entretanto, essa adoção implica na aprovação das características agronômicas pelos bananicultores, mas, acima de tudo, precisam apresentar qualidades organolépticas e de pós-colheita que atendam às exigências do consumidor.

Muitos estudos vêm sendo realizados com diferentes genótipos, em diferentes regiões do Brasil. Botelho et al. (2002), em Teresina-PI, relataram que 'Grande Naine' apresentou frutos com $21,54 \%$ de sólidos solúveis (SS), 0,34\% de acidez titulável (AT) e pH de 4,79. Os frutos de 'Nanicão' mostraram-se com teor de SS de 22,20\%,

\footnotetext{
'Eng. Agr., Doutoranda pelo Departamento de Produção Vegetal-Horticultura, Faculdade de Ciências Agronômicas/FCA/UNESP - Cx. P. 237 - CEP 18610-307 - Botucatu, SP - pitchagro@yahoo.com.br

2Professora do Departamento de Produção Vegetal-Horticultura, FCA/UNESP - Cx. P. 237 - CEP 18610-307 - Botucatu, SP - sarinel@fca.unesp.br. ${ }^{3}$ Prof ${ }^{a}$. Assistente Doutor do Depto de Bioestatística, IB - UNESP, Botucatu-SP - mmischan@ibb.unesp.br
} 
menor AT $(0,27 \%)$ e, consequentemente, maior $\mathrm{pH}(4,97)$. Frutos de 'Thap Maeo' apresentaram SS de 24,05\%, maior AT $(0,55 \%)$ e $\mathrm{pH}(4,20)$.

Cerqueira et al. (2002), em Cruz das Almas-BA, observaram que 'Tropical' apresentou frutos com firmeza de $28,0 \mathrm{~N}, \mathrm{SS} 19,44^{\circ}$ Brix e AT 0,48 \%. Os frutos de 'Nam' foram mais doces $\left(21,10^{\circ} \mathrm{Brix}\right)$, menos ácidos $(0,19 \%) \mathrm{e}$ menos firmes $(24,80 \mathrm{~N})$.

Segundo Parrela et al. (2002), no norte de Minas Gerais, 'Fhia 18' apresentou frutos com textura 5,7 $\mathrm{Kgf} \mathrm{cm}^{-2}$, pH 4,50, AT 0,56 \%, SS 20, $0{ }^{\circ}$ Brix, açúcares $14,4 \%$ e teor de amido igual a $1,04 \%$. Para as mesmas características 'Fhia 01' apresentou 5,3 $\mathrm{Kgf} \mathrm{cm}^{-2}, \mathrm{pH} 4,60$, AT 0,52\%, SS 15,5 ${ }^{\circ}$ Brix, açúcares $13,4 \%$ e teor de amido $1,47 \%$. Frutos de 'Prata Graúda' apresentaram 5,4 $\mathrm{Kgf} \mathrm{cm}^{-2}$ de textura, menor $\mathrm{pH}(4,30)$, SS de $19,6^{\circ}$ Brix, maiores valores de AT $(0,60 \%)$ e açúcares $(15,5 \%)$, e menor teor de amido $(0,97 \%)$. 'Caipira' apresentou frutos com maior textura $\left(7,3 \mathrm{Kgf} \mathrm{cm}^{-2}\right), \mathrm{SS}$ de 19,3 ${ }^{\circ}$ Brix, açúcares $14,9 \%$, maiores valores de $\mathrm{pH}(4,7)$ e amido $(2,0 \%)$.

Em Botucatu-SP, Damatto Júnior et al. (2005), relataram para frutos de 'Prata Anã', firmeza de 402,0 $\mathrm{gf} \mathrm{cm}^{-2}$, pH 4,85, AT 0,32\% e teor de SS 17,23 ${ }^{\circ}$ Brix. 'Prata Zulu' apresentou frutos mais doces $\left(23,25^{\circ} \mathrm{Brix}\right)$, no entanto, menor textura $\left(297,0 \mathrm{gf} \mathrm{cm}^{-2}\right), \mathrm{pH}(4,58)$ e AT $(0,29 \%)$. Gomes (2004) reportou para 'Prata Anã' uma textura de 906,8 gf $\mathrm{cm}^{-2}$, pH 5,86, AT 0,12\%, teor de SS 3,22 ${ }^{\circ}$ Brix, açúcares totais $2,81 \%$ e amido 22,17 \%. 'Maçã' apresentou maiores valores, respectivamente: $997,5 \mathrm{gf} \mathrm{cm}^{-2}$, pH 5,98, AT 0,15\%, SS 3,7 ${ }^{\circ}$ Brix, açúcares totais $3,16 \%$ e amido $21,95 \%$.

Sabendo da importância do estudo das características pós-colheita dos frutos, conduziu este trabalho, com o objetivo de avaliar as características físico-químicas de frutos de genótipos de bananeira, em Botucatu-SP.

O trabalho foi realizado no período de fevereiro a julho de 2007, no laboratório do Departamento de Gestão e Tecnologia Agroindustrial da FCA - UNESP, Câmpus de Botucatu-SP, que apresenta as seguintes coordenadas geográficas: Latitude $22^{\circ} 55^{\prime}$ '55' 'Sul, Longitude $48^{\circ} 26^{\prime}$ '22', Oeste e Altitude $810 \mathrm{~m}$. Foram avaliados frutos de genótipos de 3 grupos genômicos de bananeira: 'NanicãoIAC-2001', 'Grande Naine', 'Caipira' e 'Nam' (AAA); 'Maçã', 'Thap Maeo', 'Prata Anã' e 'Prata Zulu' (AAB); 'Fhia 01', 'Fhia 18', 'Prata Graúda' e 'Tropical' (AAAB), descritos na Tabela 1.

Os cachos foram colhidos no próprio pomar da faculdade, no estádio de desenvolvimento equivalente

Tabela 1 - Descrição dos genótipos de bananeira avaliados. Botucatu, SP, 2007.

\begin{tabular}{|c|c|c|}
\hline Genótipos & Grupo & Descrição \\
\hline $\begin{array}{l}\text { Nanicão- } \\
\text { IAC-2001 }\end{array}$ & AAA & $\begin{array}{l}\text { Subgrupo Cavendish, selecionado pelo IAC. É resistente à sigatoka-amarela e tolerante à } \\
\text { sigatoka-negra, imune ao mal-do-panamá e suscetível ao moko, baixa tolerância ao ataque da } \\
\text { broca-do-rizoma e do nematóide cavernícola }\end{array}$ \\
\hline $\begin{array}{l}\text { Grande } \\
\text { Naine }\end{array}$ & AAA & $\begin{array}{l}\text { Subgrupo Cavendish. É suscetível às sigatokas, aos nematóides e à broca-do-rizoma e resistente } \\
\text { ao mal-do-panamá }\end{array}$ \\
\hline Caipira & AAA & $\begin{array}{l}{ }^{3} \text { Oriundo da África Ocidental e introduzido no Brasil pela Embrapa. É resistente às sigatokas, ao } \\
\text { mal-do-panamá e à broca-do-rizoma, suscetível ao moko e ao nematóide cavernícola }\end{array}$ \\
\hline Nam & AAA & ${ }^{4}$ Introduzido da Tailândia, é resistente à sigatoka-amarela e ao mal-do-panamá \\
\hline Maça & $\mathrm{AAB}$ & $\begin{array}{l}{ }^{4} \text { É medianamente suscetível à sigatoka-amarela, mediana } \\
\text { altamente suscetível ao mal-do-panamá e ao moko e resisten }\end{array}$ \\
\hline Thap Maeo & $\mathrm{AAB}$ & $\begin{array}{l}{ }^{3} \text { Introduzido da Tailândia e selecionado pela Embrapa. Apresenta resistência às sigatokas e ao } \\
\text { mal-do-panamá, baixa incidência de broca-do-rizoma e de nematóides }\end{array}$ \\
\hline Prata Anã & $\mathrm{AAB}$ & $\begin{array}{l}\text { atokas, ao moko e ao mal-do-panamá, medianamente resistente à broca-do- } \\
\text { os nematóides }\end{array}$ \\
\hline lu & $\mathrm{AAB}$ & $\begin{array}{l}{ }^{3} \text { Originário da África. É altamente resistente às sigatokas, suscetível ao moko, mal-do-panamá, } \\
\text { broca-do-rizoma e ao nematóide cavernícola }\end{array}$ \\
\hline 1 & $\mathrm{AB}$ & ${ }^{3}$ Híbrido de 'Prata Anã', introduzido de Honduras. É resistente às sigatokas e suscetível ao moko \\
\hline Fhia 1 & $\mathrm{AB}$ & $\begin{array}{l}{ }^{4} \text { Híbrido de 'Prata Anã', introduzido de Honduras. É resistente à sigatoka-negra, medianamente } \\
\text { resistente aos nematóides, medianamente suscetível à sigatoka-amarela e à broca-do-rizoma, e } \\
\text { suscetível ao moko e ao mal-do-panamá }\end{array}$ \\
\hline $\begin{array}{l}\text { Prata } \\
\text { Graúda }\end{array}$ & AAAB & $\begin{array}{l}{ }^{4} \text { Híbrido de 'Prata Anã', introduzido de Honduras. É resistente ao mal-do-panamá, mediamanente } \\
\text { suscetível à sigatoka- amarela e sucetível ao moko e nematóides }\end{array}$ \\
\hline Tropical & $\mathrm{AB}$ & $\begin{array}{l}{ }^{4} \text { Híbrido criado pela Embrapa semelhante a 'Maça'. É resistente à sigatoka-amarela, medianamente } \\
\text { resistente aos nematóides, tolerante ao mal-do-panamá e suscetível ao moko }\end{array}$ \\
\hline
\end{tabular}

${ }^{1}$ Saes et al. (2005), ${ }^{2}$ Cordeiro (2003), ${ }^{3}$ Fancelli (2003) e ${ }^{4}$ Silva et al. (2004). 
a "3/4 gordo" (36-38 mm), dependendo do genótipo. Posteriormente, os frutos da segunda penca foram extraídos e separaram-se 5 frutos centrais para as seguintes análises laboratoriais: textura; $\mathrm{pH}$; acidez titulável; segundo metodologia do Instituto Adolfo Lutz (1985), sólidos solúveis (AOAC, 1970), amido e açúcares solúveis totais, segundo metodologia descrita por Somogyi e adaptada por Nelson (1944) e teor de potássio, conforme descrito por Malavolta et al. (1997).

Foi adotado o delineamento experimental inteiramente casualizado, com 12 tratamentos (genótipos), cinco repetições, sendo que em cada repetição utilizaramse 5 frutos. Foram realizadas as análises de variâncias e quando houve significância, o teste de tukey $(P \mathrm{~d} " 0,05)$ para a comparação entre médias de genótipos, dentro de cada grupo genômico.

Os resultados encontram-se na Tabela 2 e serão discutidos separadamente para cada característica avaliada.

\section{Textura}

Frutos dos cvs Nam, Grande Naine e Nanicão (do grupo AAA) não diferiram entre si quanto à textura, apresentando 957,40 $\mathrm{gf} \mathrm{cm}^{-2}, 920,50 \mathrm{gf} \mathrm{cm}^{-2} \mathrm{e} 919,42 \mathrm{gf}$ $\mathrm{cm}^{-2}$, respectivamente. 'Caipira' diferiu dos demais cultivares, apresentando frutos com menor textura $(789,87$ $\mathrm{gf} \mathrm{cm}^{-2}$ ).

Em relação ao grupo AAB, 'Prata Zulu' e 'Prata Anã' apresentaram frutos com maiores texturas, quando o primeiro apresentou 997,76 $\mathrm{gf} \mathrm{cm}^{-2}$ e o segundo $928,62 \mathrm{gf}$ $\mathrm{cm}^{-2}$, não diferindo entre si, porém diferindo de 'Maçã' $\left(870,38 \mathrm{gf} \mathrm{cm}^{-2}\right)$, e este, por sua vez, diferindo de 'Thap Maeo' (704,44 $\left.\mathrm{gf} \mathrm{cm}^{-2}\right)$.

Para frutos do grupo AAAB, 'Fhia 18' apresentou maior firmeza (954,50 $\left.\mathrm{g} \mathrm{cm}^{-2}\right)$, não diferindo de 'Tropical' $\left(867,36 \mathrm{gf} \mathrm{cm}^{-2}\right)$ e de 'Fhia 01' (858,62 $\left.\mathrm{gf} \mathrm{cm}^{-2}\right)$. 'Prata Graúda' apresentou frutos com menor firmeza $\left(809,00 \mathrm{gf} \mathrm{cm}^{-2}\right)$, não diferindo, porém, dos híbridos Tropical e Fhia 01.

Pereira et al. (2004), por meio da análise de correlação, verificaram que a firmeza do fruto apresentou um grau de associação de $74 \%$ com a resistência ao despencamento, significando que os frutos que são suscetíveis ao despencamento, normalmente, apresentam baixa firmeza e vice-versa. Frutos com maior textura apresentam maior resistência ao transporte, mostrando maior durabilidade póscolheita. Por meio desses relatos, pode-se deduzir que

Tabela 2 - Valores médios de textura, pH, acidez titulável (AT), sólidos solúveis (SS), açúcares solúveis totais (AST), amido e teor de potássio (K) de frutos de genótipos de bananeira de diferentes grupos genômicos, em Botucatu/SP. 2007.

\begin{tabular}{|c|c|c|c|c|c|c|c|}
\hline Genótipos & $\begin{array}{l}\text { Textura } \\
\left(\mathrm{gf} \mathrm{cm}^{-2}\right) \\
\end{array}$ & $\mathrm{pH}$ & $\operatorname{AT}(\%)$ & SS $\left({ }^{\circ}\right.$ Brix $)$ & $\operatorname{AST}(\%)$ & Amido (\%) & $\mathrm{K}\left(\mathrm{gKg}^{-1}\right)$ \\
\hline \multicolumn{8}{|c|}{ Grupo AAA } \\
\hline Nanicão & $919,42 \mathrm{~A}$ & $5,32 \mathrm{~A}$ & $0,17 \mathrm{~A}$ & $2,94 \mathrm{C}$ & $0,19 \mathrm{~A}$ & $12,10 \mathrm{~B}$ & $2,97 \mathrm{~A}$ \\
\hline GrandeNaine & $920,50 \mathrm{~A}$ & $5,48 \mathrm{~A}$ & $0,18 \mathrm{~A}$ & $3,62 \mathrm{~B}$ & $0,29 \mathrm{~A}$ & $13,45 \mathrm{AB}$ & 3,03 A \\
\hline Caipira & $789,87 \mathrm{~B}$ & $5,30 \mathrm{~A}$ & $0,14 \mathrm{~A}$ & $3,73 \mathrm{~B}$ & $0,27 \mathrm{~A}$ & $12,04 \mathrm{~B}$ & $3,41 \mathrm{~A}$ \\
\hline Nam & $957,40 \mathrm{~A}$ & $5,45 \mathrm{~A}$ & $0,14 \mathrm{~A}$ & $4,65 \mathrm{~A}$ & $0,17 \mathrm{~A}$ & $15,12 \mathrm{~A}$ & $3,25 \mathrm{~A}$ \\
\hline $\mathrm{CV}(\%)$ & 5,59 & 2,22 & 20,19 & 2,91 & 50,67 & 9,32 & 9,09 \\
\hline \multicolumn{8}{|c|}{ Grupo AAB } \\
\hline Maçã & $870,38 \mathrm{~B}$ & $5,96 \mathrm{~A}$ & $0,14 \mathrm{~A}$ & $4,20 \mathrm{~A}$ & $0,26 \mathrm{~A}$ & $16,11 \mathrm{~A}$ & $2,91 \mathrm{~B}$ \\
\hline Thap Maeo & $704,44 \mathrm{C}$ & $5,36 \mathrm{~B}$ & $0,17 \mathrm{~A}$ & $4,54 \mathrm{~A}$ & $0,46 \mathrm{~A}$ & $15,31 \mathrm{~A}$ & $3,39 \mathrm{~A}$ \\
\hline Prata Anã & $928,62 \mathrm{~A}$ & $5,92 \mathrm{~A}$ & $0,13 \mathrm{~A}$ & $3,62 \mathrm{AB}$ & $0,30 \mathrm{~A}$ & $16,07 \mathrm{~A}$ & $3,36 \mathrm{~A}$ \\
\hline Prata Zulu & $997,76 \mathrm{~A}$ & $6,00 \mathrm{~A}$ & $0,08 \mathrm{~B}$ & $3,02 \mathrm{~B}$ & $0,51 \mathrm{~A}$ & $18,27 \mathrm{~A}$ & $2,78 \mathrm{~B}$ \\
\hline $\mathrm{CV}(\%)$ & 4,63 & 2,48 & 18,15 & 7,48 & 36,53 & 13,89 & 6,39 \\
\hline \multicolumn{8}{|c|}{ Grupo AAAB } \\
\hline Fhia 01 & $858,62 \mathrm{AB}$ & $5,58 \mathrm{~A}$ & $0,14 \mathrm{~A}$ & $3,84 \mathrm{~A}$ & $0,26 \mathrm{BC}$ & $13,27 \mathrm{~A}$ & $2,92 \mathrm{~B}$ \\
\hline Fhia 18 & $954,50 \mathrm{~A}$ & $5,34 \mathrm{~A}$ & $0,18 \mathrm{~A}$ & $3,56 \mathrm{AB}$ & $0,37 \mathrm{AB}$ & $12,70 \mathrm{~A}$ & $2,91 \mathrm{~B}$ \\
\hline PrataGraúda & $809,00 \mathrm{~B}$ & $5,54 \mathrm{~A}$ & $0,14 \mathrm{~A}$ & $3,00 \mathrm{BC}$ & $0,43 \mathrm{~A}$ & $13,99 \mathrm{~A}$ & $3,22 \mathrm{~B}$ \\
\hline Tropical & $867,36 \mathrm{AB}$ & $5,52 \mathrm{~A}$ & $0,16 \mathrm{~A}$ & $2,96 \mathrm{C}$ & $0,25 \mathrm{C}$ & $14,20 \mathrm{~A}$ & $3,75 \mathrm{~A}$ \\
\hline $\mathrm{CV}(\%)$ & 6,57 & 3,46 & 24,64 & 4,71 & 20,89 & 9,06 & 6,55 \\
\hline
\end{tabular}

Médias seguidas pelas mesmas letras na coluna não diferem pelo teste de Tukey a 5\% de probabilidade. 
frutos de 'Prata Zulu' são mais resistentes ao despencamento e ao transporte $\left(997,76 \mathrm{gf} \mathrm{cm}^{-2}\right)$ e os de 'Thap Maeo' menos resistentes $\left(704,44 \mathrm{gf} \mathrm{cm}^{-2}\right)$.

pH

Segundo Palmer (1971), o pH da banana verde varia de 5,0 a 5,6 e na banana madura de 4,2 a 4,7. No entanto, dentro desses limites podem ocorrer variações nos diferentes cultivares de bananeira.

Os cultivares Grande Naine, Nam, Nanicão e Caipira, do grupo AAA, não diferiram entre si, apresentando, respectivamente, $\mathrm{pH}$ igual a 5,$48 ; 5,45 ; 5,32$ e 5,30. Os híbridos também não diferiram entre si, quando 'Fhia 01' apresentou pH 5,58, 'Prata Graúda' 5,54, 'Tropical' 5,52 e 'Fhia 18 ' 5,34. Nota-se que os valores de pH encontram-se no intervalo citado por Palmer (1971), para frutos verdes.

Em relação ao grupo AAB, 'Prata Zulu', 'Maçã' e 'Prata Anã' não diferiram entre si, apresentando, respectivamente, os seguintes valores de $\mathrm{pH}: 6,00 ; 5,96 \mathrm{e}$ 5,92 . 'Thap Maeo' apresentou frutos com menor $\mathrm{pH}(5,36)$, indicando possuir uma maior acidez.

\section{Acidez Titulável (AT)}

De acordo com Fernandes et al. (1979), Rossignoli (1983) e Bleinroth (1990), a acidez em frutos de bananeira varia de 0,17 a $0,67 \%$. Essa variação, segundo Turner (2001), ocorre porque o amadurecimento duplica e em alguns casos triplica, a acidez do fruto.

Os cultivares do grupo AAA, não diferiram entre si, quando 'Grande Naine' apresentou frutos com acidez titulável igual a 0,18 \%, 'Nanicão' 0,17 \%, 'Caipira' e 'Nam' $0,14 \%$. Também não houve diferença significativa de acidez titulável entre os híbridos (AAAB), no entanto, frutos de 'Fhia 18 ' apresentaram $0,18 \%$ de acidez, 'Tropical' $0,16 \%$, 'Fhia 01' e 'Prata Graúda' 0,14\%.

Para o grupo AAB, 'Thap Maeo' apresentou frutos com AT 0,17 \%, 'Maçã' 0,14 \% e 'Prata Anã' 0,13 \%, não diferindo entre si. 'Prata Zulu' apresentou frutos com baixa acidez $(0,08 \%)$, diferindo dos demais cultivares.

Foi possível observar que a maioria dos resultados apresentados, no presente trabalho, encontram-se no intervalo citado pela literatura $(0,17-0,67 \%)$, exceção para os frutos de 'Prata Zulu', que apresentaram uma baixa $\operatorname{acidez}(0,08 \%)$.

\section{Sólidos Solúveis (SS)}

O teor de sólidos solúveis fornece um indicativo da quantidade de açúcares existentes no fruto, considerando que outros compostos, embora em reduzidas proporções, também fazem parte, como exemplo, os ácidos, vitaminas, aminoácidos e algumas pectinas (Kluge et al., 2002).

'Nam' apresentou frutos com maior teor de sólidos solúveis $\left(4,65^{\circ} \mathrm{Brix}\right)$, diferindo dos demais cultivares. Os cvs Caipira e Grande Naine não diferiram entre si, apresentando 3,73 e 3,62 'Brix, respectivamente. 'Nanicão' apresentou frutos com o menor valor $\left(2,94^{\circ} \mathrm{Brix}\right)$, diferindo dos demais cultivares.

'Thap Maeo' e 'Maçã' não diferiram entre si, quando o primeiro apresentou frutos com $4,54^{\circ} \mathrm{Brix}$, e o segundo 4,20 ${ }^{\circ}$ Brix. 'Prata Anã' (3,62 ${ }^{\circ}$ Brix) não diferiu dos cultivares anteriores, e nem de 'Prata Zulu' (3,02 ${ }^{\circ}$ Brix).

'Fhia 01' apresentou frutos com maior teor de sólidos solúveis $\left(3,84^{\circ} \mathrm{Brix}\right)$, diferindo de 'Prata Graúda' (3,00 'Brix) e 'Tropical' (2,96 ${ }^{\circ}$ Brix $)$, porém não diferindo de 'Fhia $18^{\prime}$ (3,56 ${ }^{\circ}$ Brix $)$.

Rossignoli (1983) e Carvalho (1984) indicam teores para a banana, variando nos frutos verdes entre 1,5 a 5,2 e nos maduros entre 20,3 a 21,0 corroborando com os resultados deste trabalho para frutos verdes.

\section{Açúcares solúveis totais (AST)}

Segundo Marriot \& Palmer (1980), os açúcares que constituem normalmente 0,5 a $2 \%$ da polpa das bananas verdes, aumentam para 15 a $20 \%$ na polpa madura, em razão da degradação do amido.

Os cultivares do grupo AAA, não diferiram entre si estatisticamente. 'Grande Naine' apresentou frutos com 0,29\% de açúcares totais, 'Caipira': 0,27 \%, 'Nanicão': 0,19\% e 'Nam': 0,17\%. Os cultivares do grupo AAB, também não diferiram entre si, porém, 'Prata Zulu' apresentou maior valor $(0,51 \%)$, 'Thap Maeo': 0,46 \%, 'Prata Anã': 0,30 \% e 'Maçã': 0,26\%.

No entanto, os híbridos diferiram entre si, quando 'Prata Graúda' apresentou frutos com maiores teores de açúcares $(0,43 \%)$, não diferindo de 'Fhia 18 ' $(0,37 \%)$, e este não diferindo de 'Fhia 01 ' $(0,26 \%)$. 'Tropical' apresentou menores teores $(0,25 \%)$, não diferindo apenas de 'Fhia 01 '.

Diferenças nos valores encontrados, para as mesmas características avaliadas por diversos autores, podem ser atribuídas às condições edafoclimáticas de cultivo e também ao estádio de maturação em que foi realizada a colheita dos frutos.

\section{Amido}

Marriot \& Palmer (1980), relataram que entre 20 e $25 \%$ da polpa do fruto verde fresco é amido. Durante o processo de amadurecimento, este amido é hidrolisado quase que completamente, sendo que a polpa madura 
passa a ter entre 1 e $2 \%$ de amido. Segundo Fernandes et al. (1979) e Rossignoli (1983), os teores de amido variaram de 19,2 a 23,9\%, em frutos de banana verde.

Para o grupo AAA, 'Nam' apresentou maiores teores de amido (15,12 \%), não diferindo de 'Grande Naine' $(13,45 \%)$, e este não diferindo de 'Nanicão' $(12,10 \%)$ e 'Caipira' (12,04 \%).

Os cultivares do grupo $\mathrm{AAB}$, não diferiram estatisticamente entre si, onde 'Prata Zulu' apresentou 18,27 \%, 'Maçã' 16,11 \%, 'Prata Anã' 16,07 \% e 'Thap Maeo' $15,31 \%$. É interessante observar que esse grupo apresentou cultivares com maior porcentagem de amido.

O grupo dos híbridos (AAAB), não diferiu estatisticamente entre si. 'Tropical' apresentou 14,20\% de amido, 'Prata Graúda' 13,99 \%, 'Fhia 01' 13,27 \% e 'Fhia 18' $12,70 \%$.

\section{Potássio (K)}

Segundo Bleinroth (1990), os sais minerais apresentam pequena variação durante o amadurecimento do fruto, sendo seus teores na banana verde um pouco maiores do que no fruto maduro. A banana é considerada como uma importante fonte de potássio e, de acordo com o mesmo autor, a concentração desse mineral no fruto maduro é de 350-400 mg $100 \mathrm{~g}^{-1}$ de matéria seca, o que corresponde a $0,35-0,40 \%$.

Para o grupo AAA, os cultivares não diferiram, estatisticamente, entre si, quando 'Caipira', 'Nam', 'Grande Naine' e 'Nanicão', apresentaram 3,41 g kg ${ }^{-1}, 3,25 \mathrm{~g} \mathrm{~kg}^{-1}$, $3,03 \mathrm{~g} \mathrm{~kg}^{-1}$ e $2,97 \mathrm{~g} \mathrm{~kg}^{-1}$, respectivamente. Tal fato é importante pois, o critério 'teor de potássio nos frutos' não será um fator de exclusão na seleção dos cultivares de bananeira para o melhoramento genético e nem para o emprego comercial pelos bananicultores.

No Grupo AAB, 'Thap Maeo' e 'Prata Anã' não diferiram entre si, apresentando $3,39 \mathrm{~g} \mathrm{~kg}^{-1} \mathrm{e} 3,36 \mathrm{~g} \mathrm{~kg}^{-1}$, respectivamente. 'Maçã' e 'Prata Zulu' apresentaram valores menores, o primeiro $2,91 \mathrm{~g} \mathrm{~kg}^{-1} \mathrm{e}$ o segundo $2,78 \mathrm{~g}$ $\mathrm{kg}^{-1}$, não diferindo entre si, mas diferindo dos demais.

No Grupo AAAB, 'Tropical' apresentou maior valor $\left(3,75 \mathrm{~g} \mathrm{~kg}^{-1}\right)$, diferindo de 'Prata Graúda' $\left(3,22 \mathrm{~g} \mathrm{~kg}^{-1}\right)$, 'Fhia 01 ' $\left(2,92 \mathrm{~g} \mathrm{~kg}^{-1}\right)$ e 'Fhia 18' $\left(2,91 \mathrm{~g} \mathrm{~kg}^{-1}\right)$.

Todos os valores obtidos neste trabalho para o teor de potássio nos frutos de bananeira estão próximos aos relatados por Bleinroth (1990).

Após a discussão dos resultados, pode-se concluir que os híbridos do grupo AAAB apresentaram maiores teores de amido, quando comparados aos outros grupos genômicos. Para as outras características avaliadas não foi possível concluir qual grupo se destacou, pois cada genótipo se destacou dentro de determinada característica, onde 'Nam', do grupo AAA, apresentou frutos mais firmes, com maior teor de sólidos solúveis e amido. 'Prata Zulu', do grupo $\mathrm{AAB}$, apresentou frutos mais firmes, com menor acidez e valores maiores de açúcares solúveis totais e amido. 'Tropical', do grupo AAAB, apresentou frutos com maior teor de potássio e amido, no entanto, menor teor de sólidos solúveis e açúcares solúveis totais. Na comparação geral entre os grupo genômicos, 'Prata Zulu' apresentou maior textura, $\mathrm{pH}$, açúcares solúveis totais e amido e menor acidez.

\section{AGRADECIMENTOS}

À Fundação de Amparo à Pesquisa do Estado de São Paulo - FAPESP, pelo suporte financeiro que viabilizou a execução deste trabalho.

\section{REFERÊNCIAS BIBLIOGRÁFICAS}

ASSOCIATION OF OFFICIAL ANALYTICAL CHEMISTS. Official methods of analysis of the association of official analytical chemists. 11.ed. Washington, DC, 1970. 1015p.

BLEINROTH, E.W. Matéria prima. In: MEDINA, J.C. et al. Banana: cultura, matéria-prima, processamento e aspectos econômicos. 2.ed. rev. e ampl. Campinas: ITAL, 1990. p.179-196. (Série frutas tropicais, 3).

BOTELHO, M.A.P.; VASCONCELOS, L.F.L.; VELOSO, M.E. da C.; SOUZA, V.A.B. de; CARVALHO, J.R.P. de. Avaliação de genótipos de bananeira no estado do Piauí: qualidade de fruto. In: CONGRESSO BRASILEIRO DE FRUTICULTURA, 17., 2002, Belém. Anais... Belém: SBF, 2002. CD-ROM.

\section{CARVALHO, H.A. Qualidade de banana 'Prata' previamente armazenada em saco de polietileno, amadurecida em ambiente com elevada umidade relativa. 1984. 92f. Dissertação (Mestrado em Ciência dos Alimentos)-Escola Superior de Agricultura de Lavras, Lavras, 1984.}

CERQUEIRA, R.C.; SILVA, S. de O.; MEDINA, V.M. Características pós-colheita de frutos de genótipos de bananeira (Musa spp.). Revista Brasileira de

Fruticultura, Jaboticabal, v.24, n.3, p.654-657, dez. 2002.

CORDEIRO, Z.J.M. Cultivo da bananeira para o Estado de Rondônia: cultivares. Cruz das Almas: EmbrapaCNPTIA, 2003. Disponível em: <http:// isistemasdeproducao.cnptia.embrapa.br/Fontes Banana/BananaRondonia/index.htm? 2007 . 
DAMATTO JÚNIOR, E.R.; CAMPOS, A.J. de; MANOEL, L.; MOREIRA, G.C.; LEONEL, S.; EVANGELISTA, R.M. Produção e caracterização de frutos de bananeira 'Prata-Anã' e 'Prata-Zulu'. Revista Brasileira de Fruticultura, Jaboticabal, v.27, n.3, p.440443, dez. 2005.

FANCELLI, M. Cultivo da bananeira para o Estado do Amazonas: cultivares. Cruz das Almas: EmbrapaCNPTIA, 2003. Disponível em: <http:// isistemasdeproducao.cnptia.embrapa.br/FontesHTML' Banana/BananaAmazonas/cultivares.htmy. Acesso em: 15 jul. 2007.

FERNANDES, K.M.; CARVALHO, V.D. de; CAL-VIDAL, J. Physical changes during ripening of silver bananas. Journal of Food Science, Chicago, v.44, n.4, p.1254-1255, 1979.

GOMES, E.M. Crescimento e produção de bananeiras 'Prata Anã' e 'Maça' fertirrigadas com potássio. 2004. 76f. Tese (Doutorado em Agronomia)-Faculdade de Ciências Agronômicas, Universidade Estadual Paulista, Botucatu, 2004.

INSTITUTO ADOLFO LUTZ. Métodos químicos e físicos par a análise de alimentos. 3.ed. São Paulo, 1985. $553 \mathrm{p}$.

KLUGE, R.A.; NACHTIGAL, J.C.; FACHINELLO, J.C.; BILHALVA, A.B. Fisiologia e manejo pós-colheita de frutas de clima temperado. 2.ed. Campinas: Rural, 2002. $214 \mathrm{p}$.

MALAVOLTA, E.; VITTI, G.C.; OLIVEIRA, S.A. de. Avaliação do estado nutricional das plantas: princípios e aplicações. 2.ed. rev. e atual. Piracicaba: Potafos, 1997. $319 \mathrm{p}$.

MARRIOT, J.; PALMER, J.K. Bananas: physiology and biochemistry of storage and ripening for optimum quality. CRC Critical Review in Food Science and Nutrition, Boca Raton, v.13, n.1, p.41, Jan. 1980.
NELSON, N.A. Photometric adaptation of the Somogy method for the determination of glucose. Journal Biological Chemistry, Baltimore, n.153, p.375-380, 1944.

PALMER, J.K. The banana. In: HUME, A.C. (Ed.). The biochemistry of fruits and their products. London: Academic, 1971. v.2, p.65-101.

PARRELA, R.A. da C.; RODRIGUES, M.G.V.; LIMA, L.C.; DIAS, M.S.C.; ALMEIDA, E.F.A.; SOUZA, I.A. de; CARVALHO, M.M.; ARAÚJO, R.A.; SILVA, S. de O. e. Caracterização físico química dos frutos de genótipos de bananeira produzidos no Norte de Minas. In: CONGRESSO BRASILEIRO DE FRUTICULTURA, 17., 2002, Belém. Anais... Belém: SBF, 2002. CD-ROM.

PEREIRA, M.C.T.; SALOMÃO, L.C.C.; SILVA, S. de O. e; CECON, P.R.; PUSCHMANN, R.; JESUS, O.N. de; CERQUEIRA, R.C. Suscetibilidade à queda natural e caracterização dos frutos de diversos genótipos de bananeiras. Revista Brasileira de Fruticultura, Jaboticabal, v.26, n.3, p.499-502, dez. 2004.

ROSSIGNOLI, P.A. Atmosfera modificada por filmes de polietileno de baixa densidade com diferentes espessuras para conservação de banana 'Prata' em condições ambiente. 1983. 81f. Dissertação (Mestrado em Ciência dos Alimentos)-Escola Superior de Agricultura de Lavras, Lavras, 1983.

SAES, L.A.; NOMURA, E.S.; GARCIA, V.A. Cultivares resistentes de bananeira. In: REUNIÃO ITINERANTE DE FITOSSANIDADE DO INSTITUTO BIOLÓGICO, 13., 2005, Registro. Anais... Registro: APTA, 2005. p.51-58. Disponível em: <http://WwW.biologico.sp.gov.br/rifib/l XXIIIRifib/saes.pdif $>$. Acesso em: 16 jul. 2007.

SILVA, S. de O. e; SANTOS-SEREJO, J.A. dos; CORDEIRO, Z.J.M. Variedades. In: BORGES, A.L.; SOUZA, L. da S. (Eds.). O cultivo da bananeira. Cruz das Almas: Embrapa Mandioca e Fruticultura, 2004. p.45-58.

TURNER, D.W. Postharvest and storage of tropical and subtropical fruits: bananas and plantains. In: MITRA, S. Postharvest storage of tropical and subtropical fruits. Wallingford: CAB Internacional, 2001. p.47-77. 